\title{
Red Blood Cell Extracellular Vesicle-Based Drug Delivery: Challenges and Opportunities
}

\author{
Wararat Chiangjong ${ }^{1 \dagger}$, Pukkavadee Netsirisawan ${ }^{1 \dagger}$, Suradej Hongeng ${ }^{2}$ and \\ Somchai Chutipongtanate ${ }^{1,3,4 *}$
}

${ }^{1}$ Pediatric Translational Research Unit, Department of Pediatrics, Faculty of Medicine Ramathibodi Hospital, Mahidol University, Bangkok, Thailand, ${ }^{2}$ Division of Hematology and Oncology, Department of Pediatrics, Faculty of Medicine Ramathibodi Hospital, Mahidol University, Bangkok, Thailand, ${ }^{3}$ Department of Clinical Epidemiology and Biostatistics, Faculty of Medicine Ramathibodi Hospital, Mahidol University, Bangkok, Thailand, ${ }^{4}$ Chakri Naruebodindra Medical Institute, Faculty of Medicine Ramathibodi Hospital, Mahidol University, Bangkok, Thailand

\section{OPEN ACCESS}

Edited by:

Alice Chen

National Institutes of Health,

United States

Reviewed by:

Hongzhao Qi,

Qingdao University, China

Smart Mbagwu,

Nnamdi Azikiwe University, Nigeria

*Correspondence:

Somchai Chutipongtanate schuti.rama@gmail.com;

somchai.chu@mahidol.edu

${ }^{\dagger}$ These authors have contributed equally to this work

Specialty section:

This article was submitted to Precision Medicine,

a section of the journal

Frontiers in Medicine

Received: 19 August 2021 Accepted: 06 December 2021 Published: 24 December 2021

Citation:

Chiangjong W, Netsirisawan P, Hongeng $S$ and Chutipongtanate $S$ (2021) Red Blood Cell Extracellular

Vesicle-Based Drug Delivery:

Challenges and Opportunities.

Front. Med. 8:761362.

doi: 10.3389/fmed.2021.761362
Recently, red blood cell-derived extracellular vesicles (RBCEVs) have attracted attention for clinical applications because of their safety and biocompatibility. RBCEVs can escape macrophages through the binding of CD47 to inhibitory receptor signal regulatory protein $\alpha$. Furthermore, genetic materials such as siRNA, miRNA, mRNA, or single-stranded RNA can be encapsulated within RBCEVs and then released into target cells for precise treatment. However, their side effects, half-lives, target cell specificity, and limited large-scale production under good manufacturing practice remain challenging. In this review, we summarized the biogenesis and composition of RBCEVs, discussed the advantages and disadvantages of RBCEVs for drug delivery compared with synthetic nanovesicles and non-red blood cell-derived EVs, and provided perspectives for overcoming current limitations to the use of RBCEVs for clinical applications.

Keywords: therapeutic drug delivery, cancer, RBCEVs, extracellular vesicles, exosome, microvesicles, clinical application

\section{INTRODUCTION}

Extracellular vesicles (EVs) are cell-derived vesicles present in bodily fluids that play an essential role in intercellular communication between tumor cells and other cells within the tumor micro- and macroenvironment (1). These secreted membranous vesicles are currently separated into three main classes on the basis of their size and biogenesis as follows: (i) apoptotic bodies $(800-5,000 \mathrm{~nm}$ in diameter) released by cells undergoing programmed cell death; (ii) microvesicles (MVs; $50-1,000 \mathrm{~nm}$ in diameter), which are large membranous vesicles produced via plasma membrane budding; and (iii) exosomes (40-100 nm in diameter), which are small vesicles originating from the endosomal compartment $(2,3)$. Most cell types have been found to naturally secrete EVs under normal, physiological, and pathological conditions because of the dynamics of the cell membrane (4). Moreover, the biological functions of EVs are based on their surface composition and cellular cargo, which typically consists of bioactive molecules such as nucleic acids, lipids, and proteins. These molecules are delivered to adjacent and distant cells (5), and they lead to alterations of recipient cell fate and function and consequently modulate the surrounding microenvironment. EVs mediate functions in both healthy and disease states, as they circulate mini-messages throughout the body. For instance, healthy non-senescence mesenchymal stem cells can release EVs to repair damaged tissues and improve the stemness of the premature senescence stem 
cells $(6,7)$. EVs released from cells of the disease state contain specific molecules that could serve as biomarkers, and may also function as the mediators/aggravators of pathophysiologic processes (8-11).

EVs can be isolated from various human cells, including cancer cells, fibroblasts, epithelial cells, endothelial cells, immune cells, platelets, and red blood cells (RBCs) (12). RBCs can pass through all types of vessels and squeeze into capillaries with smaller diameters than normal RBCs for oxygen transport and carbon dioxide exchange in cells in all tissues throughout the body. RBC-derived extracellular vesicles (RBCEVs) are generated in circulation via shedding of the plasma membrane caused by complement-mediated calcium influx, followed by vesicle shedding (13). RBCEVs participate in several biological processes, such as nitric oxide (NO) homeostasis, redox balance, immunomodulation, and coagulation (14). Because they are produced from human RBCs, which practically lack both mitochondrial and nuclear DNA, RBCEVs therefore have a lower risk of horizontal gene transfer. RBCs have been widely used for blood transfusion for several decades, highlighting the potential safety and biocompatibility of RBCEVs (15). This review focuses on RBCEVs as robust nanocarriers with potential utility in future strategies as drug delivery platforms for clinical applications.

\section{RBCEV BIOGENESIS AND PRODUCTION}

Normal RBCs have a flexible biconcave shape with a diameter of 7.5-8.7 $\mu \mathrm{m}$ and thickness of 1.7-2.2 $\mu \mathrm{m}$ (16). Phospholipids, including phosphatidylcholine, phosphatidylethanolamine, sphingomyelin, and phosphatidylserine, comprise $60 \%$ of the $\mathrm{RBC}$ membrane. The remaining content consists of lipidic compartments composed of cholesterol and glycolipids, representing 30 and $10 \%$ of the membrane, respectively (17). Furthermore, the RBC membrane also contains various proteins, such as peripheral proteins (e.g., spectrins) and integral proteins (e.g., band 3, glycophorins). Additionally, RBC membrane proteins can be classified by function into three groups: cytoskeletal proteins (e.g., spectrin, actin, protein 4.1), integral structural proteins (e.g., band 3, glycophorins), and anchoring proteins (e.g., ankyrin, protein 4.2) (17). Although hemoglobins are the major cytosolic proteins of intact RBCs, the cytoplasmic fraction also contains several proteins that serve as anti-oxidant and metabolic enzymes $(18,19)$. These proteins can release adenosine triphosphate (ATP) and NO into the intracellular environment $(20,21)$. Furthermore, RBCs are also the major vesicle-secreting cells in blood circulation. During their 120-day lifespan, RBCs lose $\sim 20 \%$ of their hemoglobin content and membrane integrity during vesiculation. The physiological aging of RBCs, especially during the second half of their lifespan, accelerates vesicle generation (22). Indeed, vesiculation is one of the most important mechanisms by which RBCs eliminate any hazardous substances accumulated throughout their lifespan and prevent their early clearance from blood circulation $(23,24)$.
RBC membrane vesiculation is a homeostatic process activated in response to impaired or dangerous signaling machinery (25). This specific mechanism of vesiculation is related to the physical distortion of the $\mathrm{RBC}$ membrane caused by changes of the phospholipid organization (21). RBC vesiculation can be induced by ATP depletion, calcium loading, lysophosphatidic acid exposure, membrane protein disruption under $\mathrm{pH} 5.4$ or heating, and cross-linking with diamide, resulting in interactions among the disrupted membrane proteins/lipids and shedding of the RBC membrane to generate spectrin-depleted MVs (26-30). Other stimuli known to induce $\mathrm{RBC}$ vesiculation include oxidative injury, endotoxin, cytokines, complement, and high shear stress (31). During ATP depletion, the activity of plasma membrane $\mathrm{Ca}^{2+}$ pumps is decreased, leading to increased $\mathrm{Ca}^{2+}$ concentrations within RBCs (26). Because plasma membrane enzymes such as flippase, floppase, and scramblase must maintain membrane phospholipid asymmetry, RBC scramblase increases anionic phospholipid exposure on the external leaflet of the plasma membrane (i.e., phosphatidylserine) and then releases vesicles (32). Moreover, circulating $\mathrm{RBCs}$ can remove membrane attacking complex pore components from the plasma membrane in a process requiring $\mathrm{Ca}^{2+}$, calpain activation, and spectrin disruption via vesiculation, resulting in EV formation (33). This membrane vesiculation may occur slowly during erythrocyte aging, in the blood circulation of patients with hemolytic RBC disorders, and in stored RBCs obtained for blood transfusion (34-36). Meanwhile, RBC vesiculation may also occur in response to energy depletion and compressive force on the RBC membrane (30).

Several stimuli have been applied to reproducibly generate RBCEVs as drug carriers, although it remains unclear whether different types of stimuli may lead to various RBCEV properties. The inducing factors used to stimulate RBCs to produce RBCEVs are presented in Table $\mathbf{1}$.

\section{RBCEV COMPOSITION}

RBCEV s consist of lipid bilayer spheroids (buds) with a diameter of 100-200 nm, and they are enriched in phospholipids, proteins, cholesterol, lipid rafts, hemoglobin, and acetylcholinesterase $(37,42)$. The components of RBCEVs are derived from RBC; however, they are not identical. Compared with their parental cells, RBCEVs lack cytoskeletal-linked molecules and possess lower membrane protein content, but they retain residual hemoglobins and metabolic proteins that contribute to their various biologic effects (25). The composition of hemoglobins, including $\mathrm{HbA} 1 \mathrm{c}$, of these vesicles is similar to that of intact RBCs (43). Table 2 summarizes and compares the main components of RBC and RBCEVs.

RBCEVs contain lipid rafts and Fas-associated proteins to facilitate the action of a Fas-FADD-caspase 8-caspase 3 complex during RBC aging and death (51). The stomatinspecific lipid rafts present on RBCEVs are enriched in glycophosphatidylinositol-anchored proteins, i.e., complement decay-accelerating factor (DAF or CD55), membrane attacking 
TABLE 1 | Factors that induce RBCEV production.

\begin{tabular}{|c|c|c|c|}
\hline Inducing factors & Mechanisms & EVs characteristics & References \\
\hline $\begin{array}{l}\text { Chemical reagents } \\
\text { - Calcium ionophore } \\
\text { - Lysophosphatidic acid } \\
\text { - Phorbol } \\
\text { 12-myristate 13-acetate }\end{array}$ & $\begin{array}{l}\text { Calcium channel and protein kinase C } \\
\text { activation leads to PS exposure and MV } \\
\text { formation }\end{array}$ & $\begin{array}{l}\text { RBC morphology changes from a spherical shape to a } \\
\text { stomatocyte-, echinocyte- or discocyte-like shape. Negative } \\
\text { surface charges on EVs depend on number of PS moieties }\end{array}$ & $(30,32,37,38)$ \\
\hline $\begin{array}{l}\text { Oxidative stress } \\
\text { - tert-Butyl hydroperoxide }\end{array}$ & $\begin{array}{l}\text { Oxidative stress-induced decrease in the } \\
\text { osmotic fragility of RBCs, Hb oxidation, and EV } \\
\text { formation }\end{array}$ & $\begin{array}{l}\text { RBCEVs express PS and cell-specific band } 3 \text { epitopes on } \\
\text { their surface, as well as enzymes involved in redox } \\
\text { homeostasis and the complement-inhibiting proteins CD55 } \\
\text { and CD59 }\end{array}$ & (39) \\
\hline Long-term storage & $\begin{array}{l}\text { ATP depletion leads to changes in membrane } \\
\text { mechanical properties and metabolic depletion } \\
\text { following disturbances of } \\
\text { membrane/cytoskeleton interactions }\end{array}$ & Accumulation of oxidized proteins & $(40,41)$ \\
\hline
\end{tabular}

$P S$, phosphatidylserine; MV, microvesicle; RBC, red blood cell; EV, extracellular vesicle; RBCEV, red blood cell-derived extracellular vesicle; Hb, hemoglobin.

TABLE 2 | Comparison of the major components of RBCs and RBCEVs.

\begin{tabular}{|c|c|c|c|}
\hline Composition & RBCs & RBCEVs & References \\
\hline Size & $5-7 \mu \mathrm{m}$ & $100-300 \mathrm{~nm}$ & $(16,37)$ \\
\hline \multicolumn{4}{|l|}{ Membrane } \\
\hline $\begin{array}{l}\text { - Phospholipid } \\
\text { bilayer }\end{array}$ & PC, PE, SM, PS & PS, PE, PA & $(17,31)$ \\
\hline - Lipids & Cholesterol, glycolipids & DAG, cholesterol & $(17,44)$ \\
\hline - Proteins & $\begin{array}{l}\text { Spectrins, band 3, } \\
\text { glycophorins }\end{array}$ & $\begin{array}{l}\text { Band 3, glycophorins, } \\
\text { complement receptors, } \\
\text { GPI-anchored proteins }\end{array}$ & $(17)$ \\
\hline $\begin{array}{l}\text { - Genetic } \\
\text { materials }\end{array}$ & DNA & $\mathrm{N} / \mathrm{A}$ & (39) \\
\hline \multicolumn{4}{|l|}{ Cytoplasm } \\
\hline - DNA & $\begin{array}{l}\text { Lack both nuclear and } \\
\text { mitochondrial DNA }\end{array}$ & N/A & $(15,45)$ \\
\hline $\begin{array}{l}\text { - miRNAs (high } \\
\text { abundance) }\end{array}$ & $\begin{array}{l}\mathrm{miR}-451, \mathrm{miR}-144 \\
\mathrm{miR}-486\end{array}$ & $\begin{array}{l}\text { miR-125b-5p, } \\
\text { miR-4454, miR-451a }\end{array}$ & $(46,47)$ \\
\hline $\begin{array}{l}\text { - Proteins or } \\
\text { markers }\end{array}$ & $\begin{array}{l}\text { Hb tetramer-dimer, } \\
\text { PRX } \\
\text { oxidation-reduction, } \\
\text { NOS }\end{array}$ & Hb, synexin, sorcin & $\begin{array}{c}(18,19,48- \\
50)\end{array}$ \\
\hline
\end{tabular}

PC, phosphatidylcholine; PE, phosphatidylethanolamine; $S M$, sphingomyelin; $P S$, phosphatidylserine; Hb, hemoglobin; PA, phosphatidic acid; DAG, diacylglycerol; GPI, glycophosphatidylinositol; N/A, data not available; NOS, nitric oxide synthase; $P R X$, peroxiredoxin.

complex inhibitory protein (CD59) (52, 53). RBCEVs also express CD47 on their surfaces to inhibit phagocytosis through an interaction with the macrophage inhibitory receptor signal regulatory protein alpha $(\operatorname{SIRP} \alpha)$, thus preventing RBCEV clearance via endogenous elimination (54). RBCEVs are also enriched in synexin and sorcin, two proteins associated with stomatin-specific lipid rafts, as well as diacylglycerol and cholesterol as membrane lipids $(24,44,48)$.

Notably, the components of RBCEVs can be modified during RBC storage (47, 55, 56). Previous evidence illustrated that RBCEVs released from stored RBC units had increased surface CD47 expression and intravesicular miR4454 and miR-451a levels over time $(47,56)$. Concerning the membrane lipids, RBCEVs released after 4 weeks of RBC storage had higher ceramide, dihydroceramide, lysophosphatidylinositol, and lysophosphatidylglycerol levels, lower phosphatidylinositol and phosphatidylglycerol levels, but relatively unchanged phosphatidylethanolamine and lysophosphatidylethanolamine levels (55).

\section{RBCEV APPLICATIONS FOR DRUG DELIVERY}

Cumulative evidence suggests that RBCEVs can be applied in drug delivery systems $(15,57)$. The summary of RRBCEV production and cargo packaging for drug delivery is shown in Figure 1. RBCEVs have several advantages over conventional synthetic vehicles and non-RBC-derived EVs, all of which are discussed in this section.

\section{RBCEVs vs. Synthetic Nanovesicles}

The desired properties of drug carriers include efficient cellular entry, near-natural physicochemical properties, and the ability to evade immune responses $(58,59)$. NVs are derived from natural and synthetic vesicular carriers. The types of natural lipid NVs include exosomes, virosomes, bacterial ghosts, and erythrocyte ghosts (60). Conversely, synthetic NVs were created to mimic the physicochemical properties of liposomes (61). Liposomes contain a lipid bilayer surrounding an aqueous core to allow the encapsulation and protection of hydrophilic molecules such as miRNA or DNA (62).

Liposomes have been widely used in drug delivery because their structure can effectively entrap various drugs and then transport cargo to target sites (63). This approach has demonstrated strong therapeutic efficacy in some cancer types $(64,65)$. However, liposomes have poor selectivity for cancer cells, resulting in severe systemic side effects (66). Conjugating liposomes with specific molecules, such as ligands, antibodies, or small molecules, improves selectivity and cellular targeting (67-69). By mimicking EV properties, synthetic 


\section{Inducing factors \\ e.g., calcium ionophore, \\ PMA, oxidative stress}

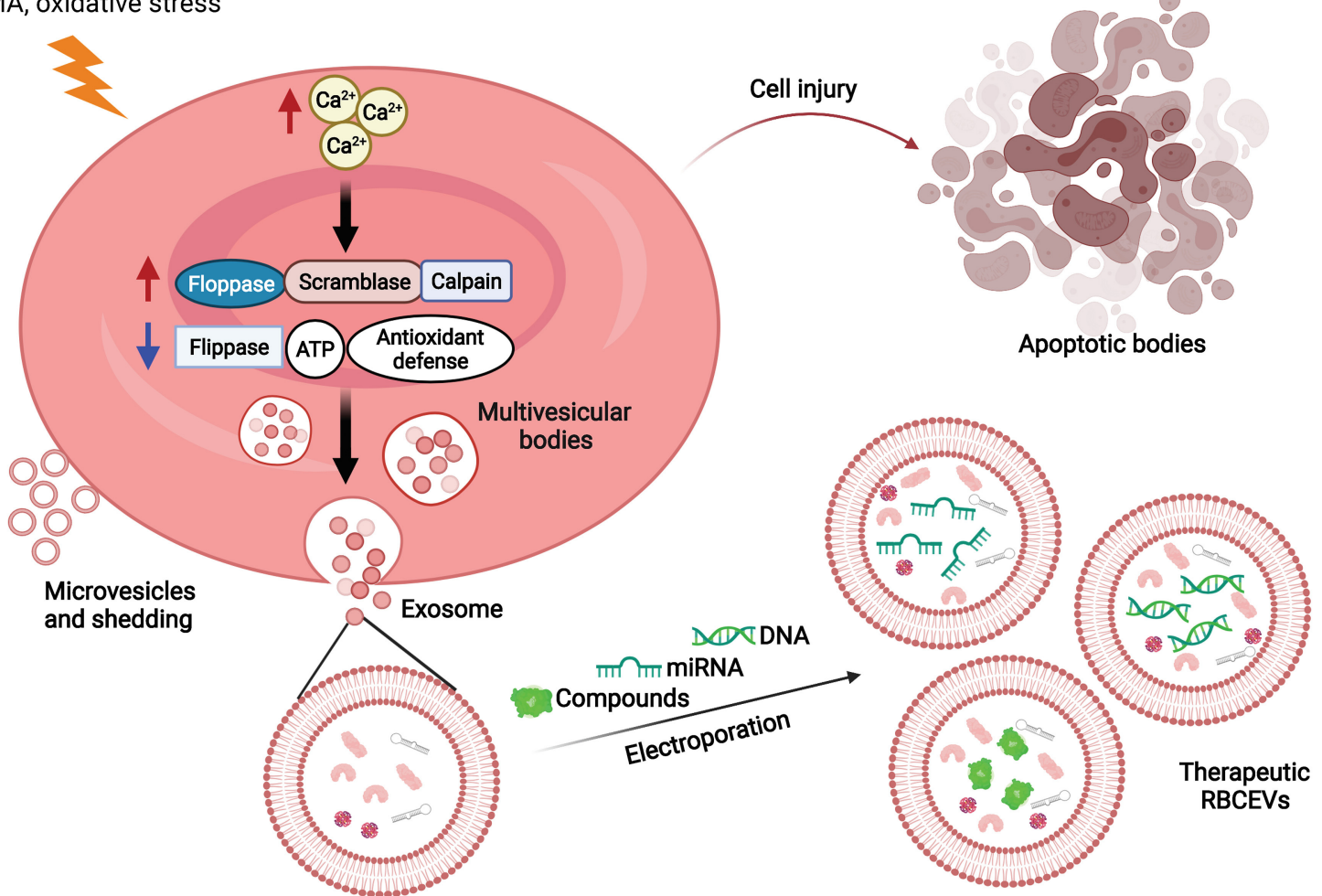

FIGURE 1 | RBCEV production and cargo packaging for drug delivery. RBCs produce extracellular vesicles in response to increasing intracellular Ca ${ }^{2+}$ concentrations. Molecular therapeutic cargo (e.g., compounds, RNA, DNA) can be packaged into RBCEVs via electroporation for drug delivery. ATP, Adenosine triphosphate; PMA, Phorbol 12-myristate 13-acetate; RBCEVs, red blood cell-derived extracellular vesicles; RBCs, red blood cells.

NVs created from biomimetic phospholipid bilayers result in several improvements such as increased solubility, prolonged action, reduced toxicity, and lower adverse effects (66, 70-72). Nonetheless, the issues limiting the utility of synthetic NVs are immunorecognition as foreign substances and immune clearance by phagocytic cells (73).

In this regard, RBCEVs have proven extremely safe, and they can be used as robust carriers clinically because of their biocompatibility (74). Regarding biosafety, biocompatibility, efficiency, accessibility, and cost-effectiveness, RBCEVs are superior to conventional RNA delivery systems such as tripartite formulations with RNA, cationic polymers, and anionic liposome-encapsulated neutral lipopolyplexes $(15,75)$. Although conventional RNA delivery systems such as lipid nanoparticles are more stable than RBCEVs, they cause toxic side effects, and they are rapidly cleared from the circulation (76). RBCEVs have been used as carriers for RNA-based therapeutics to facilitate the effective delivery of both short RNA molecules and long mRNA molecules to their target sites for cancer therapy (47). RBCEVs loaded with RNA molecules display long-term stability and retain their functional capacity for long periods (77). Moreover, RBCEVs have great potential in drug delivery platforms because they can penetrate anatomical barriers and display sufficient binding $(78,79)$. This outstanding drug delivery platform carries special properties that make it suitable for drug delivery approaches (15). Further development of cancertargeting peptide- or antibody-coated RBCEVs may result in improved target specificity and reduced adverse side effects in normal tissues. In addition to therapeutic agent delivery, RBCEV s can be applied to deliver ultra-small superparamagnetic iron oxide particles into human bone marrow mesenchymal stem cells for cellular magnetic resonance imaging to increase the performance of stem cell therapies (74). In addition, ${ }^{99} \mathrm{~m} \mathrm{Tc}$ has been delivered to white blood cells via RBCEVs to observe organ inflammation in a mouse model using a gamma camera (80). This novel strategy using RBCEVs as delivery vehicles overcomes the limitations of traditional imaging including low intracellular labeling efficiency and biosafety concerns (74).

Production upscaling is perhaps easier for synthetic NVs. However, it should be noted that RBCEV s can be easily prepared at a relatively low cost from $\mathrm{RBC}$ units available in blood banks. Chemical induction (using modalities such as calcium ionophores) to enhance RBCEV release is an interesting scalingup strategy for large-scale preparation and clinical applications $(22,81)$. Moreover, RBCEVs retain their stability and efficiency of 
delivery without any harmful effects even after multiple freezethaw cycles (82). As previously mentioned, CD47 expressed on the surface of RBCEVs prevents phagocytosis through an interaction with $\operatorname{SIRP} \alpha$ (54), thus supporting the stability of RBCEVs after intravenous administration. In addition, EVs can efficiently penetrate the blood-brain barrier (83). Signaling molecules on the RBC membrane, which is a component of RBCEVs, can inhibit immune cell engulfment via an interaction between CD47 and SIRP $\alpha$ and defend against complement system attack via C8 binding protein, homologous restriction protein, DAF, membrane cofactor protein, complement receptor 1 , and CD59 (84-86). This property of RBC membranes was applied to coat nanoparticles to increase their half-lives in blood circulation for drug delivery (87). Notably, it is feasible to prepare autologous RBCEVs for therapeutic agent loading (88).

Taken together, RBCEVs display advantages over conventional drug carriers in terms of high biocompatibility with limited immunogenicity, simple scaling-up, and high stability (15). Nonetheless, there are some disadvantages of RBCEVs for drug delivery. RBCEVs require a robust isolation method to separate them from blood cells and contaminating proteins. The heterogeneity of $\mathrm{EV}$ populations, including differences in EV size in the isolates, is nearly unavoidable depending on the isolation methods. A systematic comparison of $\mathrm{EV}$ isolation methods on the quality and quantity of plasma EVs indicated that ultracentrifugation (the gold standard) was the most appropriate method. Ultracentrifugation provided better EV purity compared to ExoQuick (System Biosciences), Total Exosome Isolation (TEI, Invitrogen), size exclusion chromatography (qEV), ultrafiltration, and exoEasy (Qiagen, membrane-based affinity binding) (89). However, the highest recovery rate was yielded by $\mathrm{qEV}(\sim 60 \%)$, while ultracentrifugation and ultrafiltration yielded $\sim 40 \%$ recovery rate (89). Polymer-based precipitation had impurity particles while exoEasy kit caused fusion and aggregation of EVs during the isolation process (89). Microfluidic and antibody selection platforms based on antigen-specific capture were successfully applied to isolate tumor-specific EVs (90). Unfortunately, microfluidic platform could separate EVs in a relatively small amount, i.e., $100 \mathrm{EVs}$ per $1 \mu \mathrm{l}$ and may cause EV aggregation during the isolation process (90). An optimized protocol for RBCEV preparation including an additional quality-control step is required to minimize batch effects and ensure the reproducibility of RBCEV applications. Notably, there is no study to clarify the normal range of EV concentration in the human body and it is unclear how various EV distributions in healthy or disease states might affect the efficacy of RBCEVbased therapy. For example, neuronal-enriched EV levels had not changed between healthy individuals and patients with Alzheimer's disease (91), so further study of RBCEV therapy in this disease context have no confounding from other EV distribution. Human lactoferrin could promote EV releasing from human adipose-derived stem cells (92), so the diseases with evidence of plasma lactoferrin changes might affect the interpretation of RBCEV therapeutic efficacy. The relationship between (exogenous) therapeutic RBCEVs and (endogenous) EV distribution should be clarified in future studies.

\section{RBCEVs vs. Non-RBC-derived EVs}

Currently, which cell types represent the best sources of EVs for drug delivery remains unclear. Because EVs carry the membrane ligands and receptors of their parental cells, different cell types may produce EVs with differing delivery proficiency and targeting selectivity (81). RBCs, endothelial cells, monocytes, granulocytes, and platelets have been reported as cell sources for EV-based drug delivery (93). Conversely, fibroblast- and dendritic cell-derived EVs are not stably obtained from all subjects $(94,95)$, whereas cancer cell lines may release EVs that promote tumor development $(96,97)$. Various circulating cell type-derived EVs, especially those derived from nucleated cells, might contain genetic material, leading to horizontal gene transfer to recipient cells (98). Whole plasma is a major source of EVs that is easily obtained and readily available. However, whole plasma-derived EVs are heterogeneous, and they may contain several (unknown) substances (42).

Blood exosomes were engineered by co-embedding of drug and cholesterol-modified miR-21 inhibitor with high payloads into the lipid bilayer of exosomes (99). Moreover, superparamagnetic molecules and targeting proteins/peptides were loaded into the exosome membrane using ligandreceptor coupling and electrostatic interactions to enhance delivery to tumor cells and then inhibit tumor growth (99, 100). For example, in Parkinson's disease treatment, the engineering blood exosomes were applied to loaded dopamine by a saturated solution incubation method into blood transferrin receptor positive exosomes which were purified by multiple superparamagnetic nanoparticles labeled with transferrin $(101,102)$. Additionally, in type 2 diabetes mellitus treatment, a potential therapeutic peptide BAY55-9837 was loaded into exosome and coupled with superparamagnetic iron oxide nanoparticles with pancreas islet targeting activity to increase insulin secretion (103).

Interestingly, several properties of RBCEVs allow them to overcome the limitations of other cell source-derived EVs. First, RBCs are easily obtained and stored for prolonged periods after blood transfusion. Second, RBCEVs have long been present as a hidden component of transfused RBCs, which highlights their safety and biocompatibility. Third, RBCEVs have a low risk of horizontal gene transfer during delivery because RBCs lack nuclear and mitochondrial DNA (44). Finally, RBCEV release can be triggered by several processes, such as membrane complement activation and calcium influx. This EV release process can be applied to produce a large number of RBCEVs for experimental and clinical applications (81). Nonetheless, RBCEVs should be considered a blood product, and as such, blood group compatibility must be considered. In this regard, autologous RBCs can be an ideal source of EVs to avoid blood group incompatibility or immunorecognition.

For allogeneic treatments in patients with cancer, RBCEVs are safer than plasma EVs because cancer and immune cells generally release an extremely large number of cancer-promoting EVs into the circulation $(96,97)$.

A comparison of drug delivery characteristics between RBCEVs and non-RBC-derived EVs is presented in Table 3. 
TABLE 3 | Comparison of drug delivery systems between RBCEVs and other EVs.

\begin{tabular}{|c|c|c|c|}
\hline Property & RBCEVs & Other EVs & Refences \\
\hline Gene transfer & ND & $\begin{array}{l}\text { Horizontal gene } \\
\text { transfer }\end{array}$ & (15) \\
\hline $\begin{array}{l}\text { Drug content } \\
\text { within EVs }\end{array}$ & $\begin{array}{l}\text { ASOs }=200 \mathrm{pmol} \\
\text { USPIO particles }= \\
200 \mu \mathrm{g}\end{array}$ & $\begin{array}{l}\text { Catalase }=0.1 \mathrm{mg} / \mathrm{mL} \\
\text { Curcumin }=2.9 \mathrm{~g} / \mathrm{g} \\
\text { Paclitaxel }=5 \mu \mathrm{M}\end{array}$ & $(15,74,104-106)$ \\
\hline $\begin{array}{l}\text { Number of } \\
\text { EVs }\end{array}$ & $1 \times 10^{11}$ & $1 \times 10^{11}$ & $(15,106)$ \\
\hline Packaging & $\begin{array}{l}\text { Electroporation, } \\
\text { hypoosmotic swelling }\end{array}$ & $\begin{array}{l}\text { Electroporation, } \\
\text { sonication, extrusion }\end{array}$ & $(15,74,107)$ \\
\hline Safety & Relatively safe & Oncogenic phenotypes & $(15,108)$ \\
\hline
\end{tabular}

RBCEV, red blood cell-derived extracellular vesicle; $E V$, extracellular vesicle; $N D$, not detectable; ASO, anti-sense oligonucleotide; USPIO, ultra-small superparamagnetic iron oxide.

\section{Drugs and Therapeutic Molecules Suitable for RBCEV-Mediated Transport}

EVs, as natural carrier systems, efficiently deliver complex molecules including proteins, nucleic acids, lipids, and sugars similarly as their parental cells $(109,110)$. Moreover, because they have similar membrane properties as their parental cells, EVs can easily internalize into parental cells as well as target cells via clathrin-independent endocytosis and macropinocytosis (109). The different cell types may use different EV uptake pathways such as membrane fusion, phagocytosis, micropinocytosis, and endocytosis (111). EVs may bind to surface receptors of targeted cells, trigger intracellular signaling cascades, and then mediate EV uptake depending on EV composition and origin (112). For example, monocyte-derived dendritic cells could uptake the milk-derived EVs via dendritic cell-specific intercellular adhesion molecule-3-grabbing non-integrin (DC-SIGN) and mucin1 (MUC1) protein interaction and phagocytosis, but not the EVs derived from other sources or lacking MUC1 (113). Furthermore, EV uptake capability depends on the recipient cell types but not the donors (114). For instance, EV uptake of human colon carcinoma cells was mediated by clathrin-dependent endocytosis, but that in human lung carcinoma cells was mediated through neither clathrin- nor caveolin-dependent endocytosis (114). However, RBCEVs can internalize into cancer cells through their primary membrane components (i.e., phospholipids) $(14,115)$. To reduce the loss of drugs/molecules during transport to target cells, RBCEVs are designed to internalize drugs/molecules and reach the target cells without inducing immune system attack and drug/molecule loss, leading to increased treatment efficacy (116).

Drugs/small molecules are easily loaded into EVs. For example, the anti-inflammatory agent curcumin was loaded into exosomes via incubation at $22^{\circ} \mathrm{C}$ for $5 \mathrm{~min}$ (105). Curcuminloaded exosomes were more stable than free curcumin in vivo following intranasal administration $(105,116)$. In addition, a heat shock technique for bacterial cell transfection (incubation on ice for $30 \mathrm{~min}$ followed by $42^{\circ} \mathrm{C}$ for $60 \mathrm{~s}$ ) and five rounds of electroporation at $500 \mathrm{~V}$ using a 10 -ms pulse were used to load miR-15a mimic/inhibitor into exosomes $(117,118)$.
The EV loading protocol should be optimized to account for differences in properties among different EV sources (119). The size of EVs may also influence the size and number of loaded drugs/molecules (120). MVs can carry larger amounts of linear and plasmid DNA than EVs following electroporation (120). Additionally, smaller linear dsDNA ( $<750 \mathrm{bp}$ ) was loaded to EVs $(85 \pm 41 \mathrm{~nm})$ at higher amounts than larger dsDNA (>1,000 bp) (120). Furthermore, miRNA loading into EVs has been optimized via incubation at $22^{\circ} \mathrm{C}$ for $2 \mathrm{~h}$ at $\mathrm{pH} 2.5$ (121). Notably, unlike miRNA loading methods of RBCEVs that were comprehensively evaluated and optimized $(15,121)$, the protocols for small molecule drug-loading into RBCEVs require further studies in a systematic manner.

\section{CHALLENGES AND LIMITATIONS OF RBCEV APPLICATIONS}

\section{Potential Side Effects}

RBCEVs may have some cellular effects because they participate in several biological processes including oxidative stress, inflammation, NO homeostasis, thrombosis, and foam cell formation (122). In oxidative stress, RBCEVs can upregulate NADPH oxidase expression via the excessive production of ROS by activated neutrophils through respiratory burst $(123,124)$. This may change cytoskeletal and cell membrane asymmetry, leading to Oxi-ERY formation and hemolysis. This can ultimately cause cholesterol release, lipid peroxidation production, and protein and iron aggregation, thereby inducing vascular cell damage $(24,125)$. Furthermore, during inflammation, components on the membrane of RBCEVs, including cholesterol (induces inflammation reaction), iron and myeloperoxidase (catalyst and source of ROS production, respectively), hemoglobin (activates pro-inflammatory transcription factor), and phospholipase $\mathrm{A}_{2}$ (hydrolyzes phospholipid, resulting in inflammatory mediator production), may cause vascular inflammation, leading to coronary heart disease (21, 125-127). In NO homeostasis, RBCEVs can induce NO synthase, resulting in excessive NO production, enhanced ROS production, increased erythrocyte adhesion, and increased endothelial cell damage and dysfunction $(128,129)$. During thrombosis, RBCEVs have pro-coagulant activity, providing a site (i.e., phosphatidylserine) for prothrombinase assembly to accelerate the coagulant cascade from prothrombin to thrombin-mediated clot formation (130). When aged or damaged RBCs enter suicidal death (eryptosis), cell shrinkage and cell membrane blebbing and scrambling lead to phosphatidylserine ("eat me" marker) exposure on the outer cell surface and then induce macrophage engulfment, thereby stimulating foam cell formation (24, 131, 132). Additionally, cholesterol on the RBC membrane can trigger foam cell formation (133). However, these aforementioned causes of vascular damage may occur when blood vessels contain high numbers of RBCEVs (134).

Drug-loaded RBCEVs are designed to significantly reduce side effects on normal cells (135). For example, RBCEVs containing miR-125b anti-sense oligonucleotides effectively antagonized 
oncomiRs and suppressed tumorigenesis without any observable side effects in breast cancer (15). In addition, RBCEVs induce pro-coagulant activity in vitro, but the effect on thrombotic complications after blood transfusion is unknown (136).

\section{Specific Cellular Targets}

In prior research, fluorescently labeled EVs could be up taken and accumulated by every cell type (137). However, EVs contain parts of the plasma membrane as their parental cells, including surface ligands and receptors. This fact highlights that EVs have specific interactions with target cells through several mechanisms such as direct fusion with the plasma membrane, endocytosis, binding to cell surface receptors and docking at the cell surface $(111,138,139)$. For these mechanisms, interactions between the surface proteins of EVs and those of recipient cells, such as that between syncytin and its receptor major facilitator superfamily domain $2 \mathrm{a}$, are required $(140,141)$.

RBCEVs bound to the target amino acid sequence can deliver drugs to specific cancer cells (135). Moreover, Plasmodium falciparum-infected RBC-derived RBCEVs loaded with drugs produced better therapeutic efficacy against malaria in vitro than normal RBCEVs loaded with drugs and free drugs (142). The specific interaction between EVs and cells depends on the origin of the EVs and the target cells under active processes (115).

\section{Half-Life and Shelf Life}

The factors influencing RBCEV release include (i) RBC storage conditions (i.e., several weeks at $4^{\circ} \mathrm{C}$ in additive solutions), (ii) donor variability, and (iii) the leukoreduction method (89). First, during RBC period, ATP concentrations inside RBCs decrease, resulting in membrane skeleton destabilization and intracellular calcium increase and leading to vesiculation (143). Moreover, the loss of endogenous anti-oxidants during RBC storage causes a number of proteins to undergo oxidative degradation such as spectrin, beta-actin, glyceraldehyde-3phosphate dehydrogenase, and band 4.1, leading to vesiculation processes $(144,145)$. Furthermore, oxidative modification has been observed in the hemoglobin-beta chain, which affects the function of hemoglobin (146). Similarly, storage at $4^{\circ} \mathrm{C}$ can inhibit the ATP-dependent activity of $\mathrm{Na}^{+} / \mathrm{K}^{+}$cationic pumps, resulting in increased $\mathrm{Na}^{+}$and $\mathrm{Ca}^{2+}$ concentrations inside cells and subsequently increased RBC vesiculation (147). Conversely, the size of RBCEVs changes during storage from $100 \mathrm{~nm}$ after 5 days up to $200 \mathrm{~nm}$ after 42 days (148). Second, donorspecific factors depend on the hematological profile, which affects the basal number of RBCEVs and level of hemolysis during packed RBC preparation. Third, the leukoreduction method affects the size and number of RBCEVs, as RBCEVs obtained via whole-blood filtration had a smaller diameter $(<200 \mathrm{~nm})$ and higher total count than those prepared using the buffy coat method (149).

The RBC half-life is $58 \pm 1.5$ days (150), whereas the clearance half-time of RBCEVs in peripheral circulation after injection using ${ }^{125} \mathrm{I}$-tagged RBCEVs is $44 \mathrm{~min}$ (83). In addition, RBCEVs remain stable and intact even after multiple freeze-thaw cycles, and they have long-term stability at $-80^{\circ} \mathrm{C}$ without effects on the moiety, uptake, and genetic material loading capacity (135).

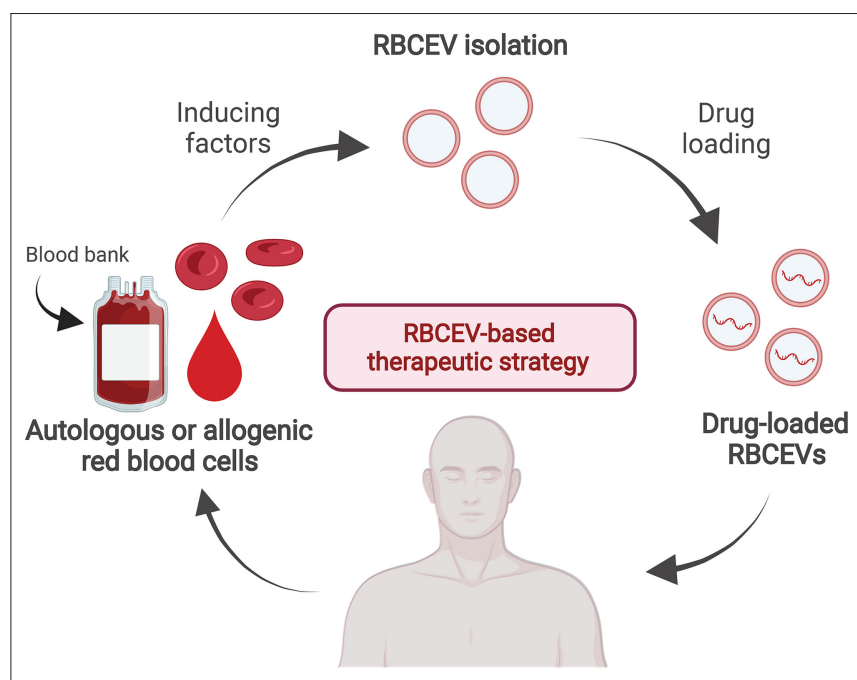

FIGURE 2 | A proposed strategy of drug-loaded RBCEV therapy. RBCs can be collected from a single patient in order to produce autologous RBCEVs and administration back after drug loading to the same patient when required. Alternatively, RBCEVs can be produced in a large scale from the blood group-matched packed red cell units released from the blood bank for the allogenic RBCEV therapy.

\section{FUTURE PROSPECTS AND CONCLUSION REMARKS}

Because the applications of EVs are not obvious, the International Society for Extracellular Vesicles aimed to standardize and develop recommendations and guidelines to improve the reproducibility of $\mathrm{EV}$ research $(151,152)$. EVs can deliver small molecules, nucleic acids, proteins, and metal nanoparticles for therapy and diagnosis (153). In addition, miRNA inside EVs is more stable than free miRNA because it is shielded from potentially damaging agents (154). Although EV-based drug delivery systems have limitations including a lack of standard isolation and purification methods, limited drugloading efficiency, and insufficient clinical-grade production, EVs have a number of advantages, such as limited immunogenicity and cytotoxicity, stability in circulation, and specific cell targeting (153). However, there is no systematic study to define a normal range of EV concentration in a human body and this could be an important research topic in future. Also, several common medications may also affect the number of $\mathrm{EV}$ distribution in the body, for example, indomethacin (a non-steroidal antiinflammatory drug for pain controlling), glibenclamide (a blood sugar lowering drug for diabetes mellitus treatment), clopidogrel (an anti-platelet medication for preventing blood clots) can inhibit EV biogenesis and release (155). These medications are potential confounding factors in the clinical EV studies.

RBCEV-based drug delivery was examined in several disease models (156). RBCEVs can be used to deliver RNA molecules to cellular targets and then release the material into the recipient cells (156). RBCEVs have been used delivery 
vehicles for gene therapy to cancer cells (26). RBCEVs have several advanced such as no risk of horizontal gene transfer (lack of both mitochondrial and nuclear DNA), extraordinary biosafety and biocompatibility, easy storage and transportation, and easy production in a large-scale and cost-effective manner (157).

In addition to drug delivery, RBCEVs may have other clinical uses, such as biomarkers for diagnosis. Human RBCEV s carrying $\alpha$-synuclein isolated from patients with Parkinson's disease can cross the blood-brain barrier and impair glutamate uptake via an interaction between excitatory amino acid transporter 2 and oligomeric $\alpha$-synuclein at astrocytic endfeet, leading to reduced synaptophysin levels in the striatum in a mouse model (158). In addition, increased numbers of RBCEVs in blood circulation can indicate hemolytic disorders such as autoimmune hemolytic anemia, complement-mediated hemolysis, malaria, and hereditary erythrocyte membrane disorders, whereas reduced counts were observed in Scott syndrome (cellular calcium abnormality) (21, 159-162). RBCEVs containing miRNA are potential biomarkers for several specific diseases such as cancers, malaria, sickle cell anemia, multiple sclerosis, and diabetes (46). Moreover, circulating MVs originating from RBCs, leukocytes, platelets, or other organs and tissues can serve as potential biomarkers for diagnosis and therapeutic monitoring during the pathogenesis of cardiometabolic diseases and coronary artery disease (163, 164). Moreover, investigating the therapeutic nature of RBCEVs could support the development of therapies combining the basal effects of RBCEVs with specific drugs/functional molecules of interest. In this direction, the RBCEV-based therapeutic strategy is proposed in Figure 2. RBCEVs can be produced from the self-RBCs (autologous) or the blood group-matched packed red cell units (allogenic) and loaded with therapeutic agents, i.e., small molecular compounds, miRNAs, or DNAs before use. Drug-loaded RBCEVs, with the full compatibility to the patients, are administered to pathological tissues in the targeted organs where the drugs are released from EVs to cure the diseases.

\section{REFERENCES}

1. Sun YZ, Ruan JS, Jiang ZS, Wang L, Wang SM. Extracellular vesicles: a new perspective in tumor therapy. Biomed Res Int. (2018) 2018:2687954. doi: 10.1155/2018/26 87954

2. Bebelman MP, Smit MJ, Pegtel DM, Baglio SR. Biogenesis and function of extracellular vesicles in cancer. Pharmacol Ther. (2018) 188:1-11. doi: 10.1016/j.pharmthera.2018. 02.013

3. Crescitelli R, Lasser C, Szabo TG, Kittel A, Eldh M, Dianzani I, et al. Distinct RNA profiles in subpopulations of extracellular vesicles: apoptotic bodies, microvesicles and exosomes. J Extracell Vesicles. (2013) 2:20677. doi: 10.3402/jev.v2i0.20677

4. Walker S, Busatto S, Pham A, Tian M, Suh A, Carson K, et al. Extracellular vesicle-based drug delivery systems for cancer treatment. Theranostics. (2019) 9:8001-17. doi: 10.7150/thno.37097
In summary, RBCEVs are derived from RBCs, and they contain small amounts of genetic material and proteins. Because of their small size and absence of horizontal gene transfer, RBCEVs represent a good delivery system for carrying drugs to cellular targets with cost-effectiveness, non-immunogenicity, and high stability and biocompatibility. Furthermore, RBCEV s can be easily targeted to every cell type, and they have a short lifespan in the body. Thus, they could be outstanding carriers for drug delivery systems in the future.

\section{AUTHOR CONTRIBUTIONS}

SC: conceptualization. WC and PN: writing-original draft preparation. $\mathrm{SH}$ and SC: writing-review and editing and supervision. WC and SC: visualization and funding acquisition. All authors contributed to the article and approved the submitted version.

\section{FUNDING}

This study was partially funded by the Office of Higher Education, Science, Research and Innovation Policy Council, Thailand (Grant Number B05F630082 to SC) and the Research Grant for New Researcher, Mahidol University, Thailand (Grant Number A11/2564 to WC). This study was supported by the Faculty of Medicine Ramathibodi Hospital, Mahidol University, Thailand. SC was also financially supported by the Faculty Staff Development Program of Faculty of Medicine Ramathibodi Hospital, Mahidol University, for his research activities. The funders had no role in the design of the study; in the collection, analyses, or interpretation of data; in the writing of the manuscript, or in the decision to publish the results.

\section{ACKNOWLEDGMENTS}

The figure was created using BioRender.com. We thank Joe Barber Jr., PhD, from Edanz (https://www.edanz.com/ac) for editing a draft of this manuscript.
5. Gurunathan S, Kang MH, Jeyaraj M, Qasim M, Kim JH. Review of the isolation, characterization, biological function, and multifarious therapeutic approaches of exosomes. Cells. (2019) 8:307. doi: 10.3390/cells8040307

6. Mas-Bargues C, Sanz-Ros J, Roman-Dominguez A, Gimeno-Mallench $\mathrm{L}$, Ingles $\mathrm{M}$, Vina $\mathrm{J}$, et al. Extracellular vesicles from healthy cells improves cell function and stemness in premature senescent stem cells by miR-302b and HIF-1alpha activation. Biomolecules. (2020) 10:957. doi: 10.3390/biom 10060957

7. Whitham M, Parker BL, Friedrichsen M, Hingst JR, Hjorth M, Hughes WE, et al. Extracellular vesicles provide a means for tissue crosstalk during exercise. Cell Metab. (2018) 27:237-51.e4. doi: 10.1016/j.cmet.2017. 12.001

8. Chen IH, Xue L, Hsu CC, Paez JS, Pan L, Andaluz H, et al. Phosphoproteins in extracellular vesicles as candidate markers for breast cancer. Proc Natl Acad Sci USA. (2017) 114:3175-80. doi: 10.1073/pnas.1618088114

9. Joncas FH, Lucien F, Rouleau M, Morin F, Leong HS, Pouliot F, et al. Plasma extracellular vesicles as phenotypic biomarkers in prostate 
cancer patients. Prostate. (2019) 79:1767-76. doi: 10.1002/pros. 23901

10. Raeven P, Zipperle J, Drechsler S. Extracellular vesicles as markers and mediators in sepsis. Theranostics. (2018) 8:3348-65. doi: 10.7150/thno.23453

11. Muraoka S, DeLeo AM, Sethi MK, Yukawa-Takamatsu K, Yang Z, Ko J, et al. Proteomic and biological profiling of extracellular vesicles from Alzheimer's disease human brain tissues. Alzheimers Dement. (2020) 16:896907. doi: 10.1002/alz.12089

12. Fais S, Logozzi M, Lugini L, Federici C, Azzarito T, Zarovni N, et al. Exosomes: the ideal nanovectors for biodelivery. Biol Chem. (2013) 394:1-15. doi: 10.1515/hsz-2012-0236

13. Wannez A, Devalet B, Chatelain B, Chatelain C, Dogne JM, Mullier F. Extracellular vesicles in red blood cell concentrates: an overview. Transfus Med Rev. (2019) 33:125-30. doi: 10.1016/j.tmrv.2019.02.002

14. Thangaraju K, Neerukonda SN, Katneni U, Buehler PW. Extracellular vesicles from red blood cells and their evolving roles in health, coagulopathy and therapy. Int J Mol Sci. (2020) 22:153. doi: 10.3390/ijms22010153

15. Usman WM, Pham TC, Kwok YY, Vu LT, Ma V, Peng B, et al. Efficient RNA drug delivery using red blood cell extracellular vesicles. Nat Commun. (2018) 9:2359. doi: 10.1038/s41467-018-04791-8

16. Diez-Silva M, Dao M, Han J, Lim CT, Suresh S. Shape and biomechanical characteristics of human red blood cells in health and disease. MRS Bull. (2010) 35:382-8. doi: $10.1557 / \mathrm{mrs} 2010.571$

17. de Oliveira S, Saldanha C. An overview about erythrocyte membrane. Clin Hemorheol Microcirc. (2010) 44:63-74. doi: 10.3233/CH-2010-1253

18. Pallotta V, D’Alessandro A, Rinalducci S, Zolla L. Native protein complexes in the cytoplasm of red blood cells. J Proteome Res. (2013) 12:3529-46. doi: $10.1021 / \mathrm{pr} 400431 \mathrm{~b}$

19. Kakhniashvili DG, Bulla LA Jr, Goodman SR. The human erythrocyte proteome: analysis by ion trap mass spectrometry. Mol Cell Proteomics. (2004) 3:501-9. doi: 10.1074/mcp.M300132-MCP200

20. Donadee C, Raat NJ, Kanias T, Tejero J, Lee JS, Kelley EE, et al. Nitric oxide scavenging by red blood cell microparticles and cell-free hemoglobin as a mechanism for the red cell storage lesion. Circulation. (2011) 124:465-76. doi: 10.1161/CIRCULATIONAHA.110.008698

21. Alaarg A, Schiffelers RM, van Solinge WW, van Wijk R. Red blood cell vesiculation in hereditary hemolytic anemia. Front Physiol. (2013) 4:365. doi: 10.3389/fphys.2013.00365

22. Antonelou MH, Seghatchian J. Update on extracellular vesicles inside red blood cell storage units: adjust the sails closer to the new wind. Transfus Apher Sci. (2016) 55:92-104. doi: 10.1016/j.transci.2016. 07.016

23. Bosman GJ, Lasonder E, Luten M, Roerdinkholder-Stoelwinder B, Novotny $\mathrm{VM}$, Bos $\mathrm{H}$, et al. The proteome of red cell membranes and vesicles during storage in blood bank conditions. Transfusion. (2008) 48:827-35. doi: 10.1111/j.1537-2995.2007.01630.x-i2

24. Willekens FL, Werre JM, Groenen-Dopp YA, RoerdinkholderStoelwinder B, de Pauw B, Bosman GJ. Erythrocyte vesiculation: a self-protective mechanism? $\mathrm{Br} J$ Haematol. (2008) 141:549-56. doi: 10.1111/j.1365-2141.2008.07055.x

25. Bosman GJ, Willekens FL, Werre JM. Erythrocyte aging: a more than superficial resemblance to apoptosis? Cell Physiol Biochem. (2005) 16:1-8. doi: $10.1159 / 000087725$

26. Said AS, Doctor A. Influence of red blood cell-derived microparticles upon vasoregulation. Blood Transfus. (2017) 15:522-34. doi: 10.2450/2017.0353-16

27. Kabaso D, Shlomovitz R, Auth T, Lew VL, Gov NS. Curling and local shape changes of red blood cell membranes driven by cytoskeletal reorganization. Biophys J. (2010) 99:808-16. doi: 10.1016/j.bpj.2010. 04.067

28. Jaferzadeh K, Sim M, Kim N, Moon I. Quantitative analysis of three-dimensional morphology and membrane dynamics of red blood cells during temperature elevation. Sci Rep. (2019) 9:14062. doi: 10.1038/s41598-019-50640-z

29. Pantaleo A, Ferru E, Giribaldi G, Mannu F, Carta F, Matte A, et al. Oxidized and poorly glycosylated band 3 is selectively phosphorylated by Syk kinase to form large membrane clusters in normal and G6PD-deficient red blood cells. Biochem J. (2009) 418:359-67. doi: 10.1042/BJ20081557
30. Salzer U, Zhu R, Luten $M$, Isobe $H$, Pastushenko V, Perkmann $\mathrm{T}$, et al. Vesicles generated during storage of red cells are rich in the lipid raft marker stomatin. Transfusion. (2008) 48:451-62. doi: 10.1111/j.1537-2995.2007.01549.x

31. Westerman M, Porter JB. Red blood cell-derived microparticles: an overview. Blood Cells Mol Dis. (2016) 59:134-9. doi: 10.1016/j.bcmd.2016.04.003

32. Nguyen DB, Wagner-Britz L, Maia S, Steffen P, Wagner C, Kaestner L, et al. Regulation of phosphatidylserine exposure in red blood cells. Cell Physiol Biochem. (2011) 28:847-56. doi: 10.1159/000335798

33. Iida $\mathrm{K}$, Whitlow MB, Nussenzweig V. Membrane vesiculation protects erythrocytes from destruction by complement. J Immunol. (1991) 147:2638-42.

34. Asaro RJ, Zhu Q, Cabrales P. Erythrocyte aging, protection via vesiculation: an analysis methodology via oscillatory flow. Front Physiol. (2018) 9:1607. doi: 10.3389/fphys.2018.01607

35. Huisjes R, Bogdanova A, van Solinge WW, Schiffelers RM, Kaestner L, van Wijk R. Squeezing for life - properties of red blood cell deformability. Front Physiol. (2018) 9:656. doi: 10.3389/fphys.2018.00656

36. Lauren E, Tigistu-Sahle F, Valkonen S, Westberg M, Valkeajarvi A, Eronen J, et al. Phospholipid composition of packed red blood cells and that of extracellular vesicles show a high resemblance and stability during storage. Biochim Biophys Acta Mol Cell Biol Lipids. (2018) 1863:1-8. doi: 10.1016/j.bbalip.2017.09.012

37. Nguyen DB, Ly TB, Wesseling MC, Hittinger M, Torge A, Devitt A, et al. Characterization of microvesicles released from human red blood cells. Cell Physiol Biochem. (2016) 38:1085-99. doi: 10.1159/000443059

38. Philipson L, Zetterqvist $O$. The presence of DNA in human erythrocyte membranes. Biochim Biophys Acta. (1964) 91:171-3. doi: 10.1016/0926-6550(64)90185-9

39. Sudnitsyna J, Skverchinskaya E, Dobrylko I, Nikitina E, Gambaryan S, Mindukshev I. Microvesicle formation induced by oxidative stress in human erythrocytes. Antioxidants. (2020) 9:929. doi: 10.3390/antiox9100929

40. Meiselman HJ, Evans EA, Hochmuth RM. Membrane mechanical properties of ATP-depleted human erythrocytes. Blood. (1978) 52:499-504. doi: 10.1182/blood.V52.3.499.499

41. Prudent M, Crettaz D, Delobel J, Seghatchian J, Tissot JD, Lion N. Differences between calcium-stimulated and storage-induced erythrocyte-derived microvesicles. Transfus Apher Sci. (2015) 53:153-8. doi: $10.1016 /$ j.transci.2015.10.012

42. Arraud N, Linares R, Tan S, Gounou C, Pasquet JM, Mornet S, et al. Extracellular vesicles from blood plasma: determination of their morphology, size, phenotype and concentration. J Thromb Haemost. (2014) 12:614-27. doi: 10.1111/jth.12554

43. Bosman GJ, Werre JM, Willekens FL, Novotny VM. Erythrocyte ageing in vivo and in vitro: structural aspects and implications for transfusion. Transfus Med. (2008) 18:335-47. doi: 10.1111/j.1365-3148.2008.00892.x

44. Tissot JD, Rubin O, Canellini G. Analysis and clinical relevance of microparticles from red blood cells. Curr Opin Hematol. (2010) 17:571-7. doi: 10.1097/MOH.0b013e32833ec217

45. Shi J, Kundrat L, Pishesha N, Bilate A, Theile C, Maruyama T, et al. Engineered red blood cells as carriers for systemic delivery of a wide array of functional probes. Proc Natl Acad Sci USA. (2014) 111:10131-6. doi: 10.1073/pnas.1409861111

46. Sun L, Yu Y, Niu B, Wang D. Red blood cells as potential repositories of microRNAs in the circulatory system. Front Genet. (2020) 11:442. doi: 10.3389/fgene.2020.00442

47. Huang H, Zhu J, Fan L, Lin Q, Fu D, Wei B, et al. MicroRNA profiling of exosomes derived from red blood cell units: implications in transfusionrelated immunomodulation. Biomed Res Int. (2019) 2019:2045915. doi: $10.1155 / 2019 / 2045915$

48. Salzer U, Hinterdorfer P, Hunger U, Borken C, Prohaska R. Ca(++)dependent vesicle release from erythrocytes involves stomatin-specific lipid rafts, synexin (annexin VII), and sorcin. Blood. (2002) 99:2569-77. doi: 10.1182/blood.V99.7.2569

49. Kleinbongard P, Schulz R, Rassaf T, Lauer T, Dejam A, Jax T, et al. Red blood cells express a functional endothelial nitric oxide synthase. Blood. (2006) 107:2943-51. doi: 10.1182/blood-2005-10-3992 
50. O'Neill JS, Reddy AB. Circadian clocks in human red blood cells. Nature. (2011) 469:498-503. doi: 10.1038/nature09702

51. Kriebardis AG, Antonelou MH, Stamoulis KE, Economou-Petersen E, Margaritis LH, Papassideri IS. RBC-derived vesicles during storage: ultrastructure, protein composition, oxidation, and signaling components. Transfusion. (2008) 48:1943-53. doi: 10.1111/j.1537-2995.2008.01794.x

52. Clayton A, Harris CL, Court J, Mason MD, Morgan BP. Antigenpresenting cell exosomes are protected from complement-mediated lysis by expression of CD55 and CD59. Eur J Immunol. (2003) 33:522-31. doi: $10.1002 / \mathrm{immu.200310028}$

53. Rabesandratana $\mathrm{H}$, Toutant JP, Reggio H, Vidal M. Decay-accelerating factor (CD55) and membrane inhibitor of reactive lysis (CD59) are released within exosomes during in vitro maturation of reticulocytes. Blood. (1998) 91:257380. doi: 10.1182/blood.V91.7.2573

54. Burger P, Hilarius-Stokman P, de Korte D, van den Berg TK, van Bruggen R. CD47 functions as a molecular switch for erythrocyte phagocytosis. Blood. (2012) 119:5512-21. doi: 10.1182/blood-2011-10-386805

55. Cloos AS, Ghodsi M, Stommen A, Vanderroost J, Dauguet N, Pollet $\mathrm{H}$, et al. Interplay between plasma membrane lipid alteration, oxidative stress and calcium-based mechanism for extracellular vesicle biogenesis from erythrocytes during blood storage. Front Physiol. (2020) 11:712. doi: 10.3389/fphys.2020.00712

56. Gamonet C, Desmarets M, Mourey G, Biichle S, Aupet S, Laheurte $\mathrm{C}$, et al. Processing methods and storage duration impact extracellular vesicle counts in red blood cell units. Blood Adv. (2020) 4:5527-39. doi: 10.1182/bloodadvances.2020001658

57. Zhang G, Huang X, Xiu H, Sun Y, Chen J, Cheng G, et al. Extracellular vesicles: natural liver-accumulating drug delivery vehicles for the treatment of liver diseases. J Extracell Vesicles. (2020) 10:e12030. doi: $10.1002 /$ jev2.12030

58. Fernandes M, Lopes I, Teixeira J, Botelho C, Gomes AC. Exosome-like nanoparticles: a new type of nanocarrier. Curr Med Chem. (2020) 27:3888905. doi: 10.2174/0929867326666190129142604

59. Zhang P, Zhang L, Qin Z, Hua S, Guo Z, Chu C, et al. Genetically engineered liposome-like nanovesicles as active targeted transport platform. Adv Mater. (2018) 30:1705350. doi: 10.1002/adma.201705350

60. Mi P, Zhang P, Liu G. Bio-inspired virus-like nanovesicle for effective vaccination. Hum Vaccin Immunother. (2016) 12:2090-1. doi: $10.1080 / 21645515.2016 .1157244$

61. Royes J, Ilioaia O, Lubart Q, Angius F, Dubacheva GV, Bally M, et al. Bacteriabased production of thiol-clickable, genetically encoded lipid nanovesicles. Angew Chem Int Ed Engl. (2019) 58:7395-9. doi: 10.1002/anie.2019 02929

62. Soltani F, Parhiz H, Mokhtarzadeh A, Ramezani M. Synthetic and biological vesicular nano-carriers designed for gene delivery. Curr Pharm Des. (2015) 21:6214-35. doi: 10.2174/1381612821666151027153410

63. Weinstein JN, Leserman LD. Liposomes as drug carriers in cancer chemotherapy. Pharmacol Ther. (1984) 24:207-33. doi: 10.1016/0163-7258(84)90035-4

64. An D, Yu X, Jiang L, Wang R, He P, Chen N, et al. Reversal of multidrug resistance by apolipoprotein A1-modified doxorubicin liposome for breast cancer treatment. Molecules. (2021) 26:1280. doi: 10.3390/molecules 26051280

65. Pinho JO, da Silva IV, Amaral JD, Rodrigues CMP, Casini A, Soveral G, et al. Therapeutic potential of a copper complex loaded in $\mathrm{pH}$-sensitive long circulating liposomes for colon cancer management. Int J Pharm. (2021) 599:120463. doi: 10.1016/j.ijpharm.2021.120463

66. Fleury A, Martinez MC, Le Lay S. Extracellular vesicles as therapeutic tools in cardiovascular diseases. Front Immunol. (2014) 5:370. doi: 10.3389/fimmu.2014.00370

67. Leung K. Sialyl-Lewis(x)-liposome-Cy5.5. Molecular Imaging and Contrast Agent Database (MICAD). Bethesda, MD: National Center for Biotechnology Information (2004).

68. Dasa SSK, Suzuki R, Gutknecht M, Brinton LT, Tian Y, Michaelsson E, et al. Development of target-specific liposomes for delivering small molecule drugs after reperfused myocardial infarction. J Control Release. (2015) 220:556-67. doi: 10.1016/j.jconrel.2015.06.017
69. Puri A, Kramer-Marek G, Campbell-Massa R, Yavlovich A, Tele SC, Lee $\mathrm{SB}$, et al. HER2-specific affibody-conjugated thermosensitive liposomes (Affisomes) for improved delivery of anticancer agents. J Liposome Res. (2008) 18:293-307. doi: 10.1080/08982100802457377

70. Sakai-Kato K, Yoshida K, Takechi-Haraya Y, Izutsu KI. Physicochemical characterization of liposomes that mimic the lipid composition of exosomes for effective intracellular trafficking. Langmuir. (2020) 36:1273544. doi: 10.1021/acs.langmuir.0c02491

71. Kooijmans SA, Vader P, van Dommelen SM, van Solinge WW, Schiffelers RM. Exosome mimetics: a novel class of drug delivery systems. Int $J$ Nanomed. (2012) 7:1525-41. doi: 10.2147/IJN.S 29661

72. Vazquez-Rios AJ, Molina-Crespo A, Bouzo BL, Lopez-Lopez R, Moreno-Bueno G, de la Fuente M. Exosome-mimetic nanoplatforms for targeted cancer drug delivery. J Nanobiotechnol. (2019) 17:85. doi: 10.1186/s12951-019-0517-8

73. Lai RC, Yeo RW, Tan KH, Lim SK. Exosomes for drug delivery - a novel application for the mesenchymal stem cell. Biotechnol Adv. (2013) 31:543-51. doi: 10.1016/j.biotechadv.2012.08.008

74. Chang M, Hsiao JK, Yao M, Chien LY, Hsu SC, Ko BS, et al. Homologous RBC-derived vesicles as ultrasmall carriers of iron oxide for magnetic resonance imaging of stem cells. Nanotechnology. (2010) 21:235103. doi: $10.1088 / 0957-4484 / 21 / 23 / 235103$

75. Perche F, Clemencon R, Schulze K, Ebensen T, Guzman CA, Pichon C. Neutral lipopolyplexes for in vivo delivery of conventional and replicative RNA vaccine. Mol Ther Nucleic Acids. (2019) 17:767-75. doi: 10.1016/j.omtn.2019.07.014

76. Wan C, Allen TM, Cullis PR. Lipid nanoparticle delivery systems for siRNA-based therapeutics. Drug Deliv Transl Res. (2014) 4:74-83. doi: 10.1007/s13346-013-0161-z

77. Koopaei NN, Chowdhury EA, Jiang J, Noorani B, da Silva L, Bulut G, et al. Enrichment of the erythrocyte miR-451a in brain extracellular vesicles following impairment of the blood-brain barrier. Neurosci Lett. (2021) 751:135829. doi: 10.1016/j.neulet.2021.1 35829

78. Mantel PY, Hjelmqvist D, Walch M, Kharoubi-Hess S, Nilsson S, Ravel $\mathrm{D}$, et al. Infected erythrocyte-derived extracellular vesicles alter vascular function via regulatory Ago2-miRNA complexes in malaria. Nat Commun. (2016) 7:12727. doi: 10.1038/ncomms 12727

79. Oliveira GP, Jr., Zigon E, Rogers G, Davodian D, Lu S, et al. Detection of extracellular vesicle RNA using molecular beacons. iScience. (2020) 23:100782. doi: 10.1016/j.isci.2019.1 00782

80. Son SH, Oh JM, Gangadaran P, Ji HD, Lee HW, Rajendran RL, et al. White blood cell labeling with Technetium-99m $((99 \mathrm{~m}) \mathrm{Tc})$ using red blood cell extracellular vesicles-mimetics. Blood Cells Mol Dis. (2020) 80:102375. doi: 10.1016/j.bcmd.2019.102375

81. Kuo WP, Tigges JC, Toxavidis V, Ghiran I. Red blood cells: a source of extracellular vesicles. Methods Mol Biol. (2017) 1660:15-22. doi: 10.1007/978-1-4939-7253-1_2

82. Jeyaram A, Jay SM. Preservation and storage stability of extracellular vesicles for therapeutic applications. AAPS J. (2017) 20:1. doi: 10.1208/s12248-017-0160-y

83. Matsumoto J, Stewart T, Sheng L, Li N, Bullock K, Song N, et al. Transmission of alpha-synuclein-containing erythrocyte-derived extracellular vesicles across the blood-brain barrier via adsorptive mediated transcytosis: another mechanism for initiation and progression of Parkinson's disease? Acta Neuropathol Commun. (2017) 5:71. doi: 10.1186/s40478-0170470-4

84. Barclay AN, Van den Berg TK. The interaction between signal regulatory protein alpha (SIRPalpha) and CD47: structure, function, and therapeutic target. Annu Rev Immunol. (2014) 32:25-50. doi: 10.1146/annurev-immunol-032713-120142

85. Schonermark S, Rauterberg EW, Shin ML, Loke S, Roelcke D, Hansch GM. Homologous species restriction in lysis of human erythrocytes: a membranederived protein with C8-binding capacity functions as an inhibitor. $J$ Immunol. (1986) 136:1772-6. 
86. Zalman LS, Wood LM, Muller-Eberhard HJ. Isolation of a human erythrocyte membrane protein capable of inhibiting expression of homologous complement transmembrane channels. Proc Natl Acad Sci USA. (1986) 83:6975-9. doi: 10.1073/pnas.83.18.6975

87. Xia Q, Zhang Y, Li Z, Hou X, Feng N. Red blood cell membrane-camouflaged nanoparticles: a novel drug delivery system for antitumor application. Acta Pharm Sin B. (2019) 9:675-89. doi: 10.1016/j.apsb.2019.01.011

88. Nazimek K, Bustos-Moran E, Blas-Rus N, Nowak B, Ptak W, Askenase PW, et al. Syngeneic red blood cell-induced extracellular vesicles suppress delayed-type hypersensitivity to self-antigens in mice. Clin Exp Allergy. (2019) 49:1487-99. doi: 10.1111/cea.13475

89. Tian Y, Gong M, Hu Y, Liu H, Zhang W, Zhang M, et al. Quality and efficiency assessment of six extracellular vesicle isolation methods by nano-flow cytometry. J Extracell Vesicles. (2020) 9:1697028. doi: 10.1080/20013078.2019.1697028

90. Reategui E, van der Vos KE, Lai CP, Zeinali M, Atai NA, Aldikacti B, et al. Engineered nanointerfaces for microfluidic isolation and molecular profiling of tumor-specific extracellular vesicles. Nat Commun. (2018) 9:175. doi: 10.1038/s41467-017-02261-1

91. Kapogiannis D, Mustapic M, Shardell MD, Berkowitz ST, Diehl TC, Spangler $\mathrm{RD}$, et al. Association of extracellular vesicle biomarkers with Alzheimer disease in the Baltimore longitudinal study of aging. JAMA Neurol. (2019) 76:1340-51. doi: 10.1001/jamaneurol.2019.2462

92. Kim J, You GE, Woo M, Chang NH, Lee J. Discovery of lactoferrin as a stimulant for hADSC-derived EV secretion and proof of enhancement of resulting EVs through skin model. Int J Mol Sci. (2021) 22:10993. doi: 10.3390/ijms222010993

93. Chatterjee V, Yang X, Ma Y, Wu MH, Yuan SY. Extracellular vesicles: new players in regulating vascular barrier function. Am J Physiol Heart Circ Physiol. (2020) 319:H1181-H96. doi: 10.1152/ajpheart.00579.2020

94. Alvarez-Erviti L, Seow Y, Yin H, Betts C, Lakhal S, Wood MJ. Delivery of siRNA to the mouse brain by systemic injection of targeted exosomes. Nat Biotechnol. (2011) 29:341-5. doi: 10.1038/nbt.1807

95. Kamerkar S, LeBleu VS, Sugimoto H, Yang S, Ruivo CF, Melo SA, et al. Exosomes facilitate therapeutic targeting of oncogenic KRAS in pancreatic cancer. Nature. (2017) 546:498-503. doi: 10.1038/nature22341

96. Kalluri R. The biology and function of exosomes in cancer. J Clin Invest. (2016) 126:1208-15. doi: 10.1172/JCI81135

97. Kosaka N, Yoshioka Y, Fujita Y, Ochiya T. Versatile roles of extracellular vesicles in cancer. J Clin Invest. (2016) 126:1163-72. doi: 10.1172/JCI81130

98. Wahlgren J, De LKT, Brisslert M, Vaziri Sani F, Telemo E, Sunnerhagen $\mathrm{P}$, et al. Plasma exosomes can deliver exogenous short interfering RNA to monocytes and lymphocytes. Nucleic Acids Res. (2012) 40:e130. doi: 10.1093/nar/gks463

99. Zhan Q, Yi K, Qi H, Li S, Li X, Wang Q, et al. Engineering blood exosomes for tumor-targeting efficient gene/chemo combination therapy. Theranostics. (2020) 10:7889-905. doi: 10.7150/thno.45028

100. Qi H, Liu C, Long L, Ren Y, Zhang S, Chang X, et al. Blood exosomes endowed with magnetic and targeting properties for cancer therapy. ACS Nano. (2016) 10:3323-33. doi: 10.1021/acsnano.5b06939

101. Qu M, Lin Q, Huang L, Fu Y, Wang L, He S, et al. Dopamine-loaded blood exosomes targeted to brain for better treatment of Parkinson's disease. $J$ Control Release. (2018) 287:156-66. doi: 10.1016/j.jconrel.2018.08.035

102. Yang L, Han D, Zhan Q, Li X, Shan P, Hu Y, et al. Blood TfR+ exosomes separated by a $\mathrm{pH}$-responsive method deliver chemotherapeutics for tumor therapy. Theranostics. (2019) 9:7680-96. doi: 10.7150/thno.37220

103. Zhuang M, Du D, Pu L, Song H, Deng M, Long Q, et al. SPIONdecorated exosome delivered BAY55-9837 targeting the pancreas through magnetism to improve the blood GLC response. Small. (2019) 15:e1903135. doi: $10.1002 /$ smll.201903135

104. Haney MJ, Klyachko NL, Zhao Y, Gupta R, Plotnikova EG, He Z, et al. Exosomes as drug delivery vehicles for Parkinson's disease therapy. J Control Release. (2015) 207:18-30. doi: 10.1016/j.jconrel.2015.03.033

105. Sun D, Zhuang X, Xiang X, Liu Y, Zhang S, Liu C, et al. A novel nanoparticle drug delivery system: the anti-inflammatory activity of curcumin is enhanced when encapsulated in exosomes. Mol Ther. (2010) 18:1606-14. doi: $10.1038 / \mathrm{mt} .2010 .105$
106. Saari H, Lazaro-Ibanez E, Viitala T, Vuorimaa-Laukkanen E, Siljander P, Yliperttula M. Microvesicle- and exosome-mediated drug delivery enhances the cytotoxicity of Paclitaxel in autologous prostate cancer cells. J Control Release. (2015) 220:727-37. doi: 10.1016/j.jconrel.2015.09.031

107. Zhang YF, Shi JB, Li C. Small extracellular vesicle loading systems in cancer therapy: current status and the way forward. Cytotherapy. (2019) 21:1122-36. doi: $10.1016 /$ j.jcyt.2019.10.002

108. Balaj L, Lessard R, Dai L, Cho YJ, Pomeroy SL, Breakefield XO, et al. Tumour microvesicles contain retrotransposon elements and amplified oncogene sequences. Nat Commun. (2011) 2:180. doi: 10.1038/ncomms1180

109. Costa Verdera H, Gitz-Francois JJ, Schiffelers RM, Vader P. Cellular uptake of extracellular vesicles is mediated by clathrin-independent endocytosis and macropinocytosis. J Control Release. (2017) 266:100-8. doi: 10.1016/j.jconrel.2017.09.019

110. Yanez-Mo M, Siljander PR, Andreu Z, Zavec AB, Borras FE, Buzas EI, et al. Biological properties of extracellular vesicles and their physiological functions. J Extracell Vesicles. (2015) 4:27066. doi: 10.3402/jev.v4.27066

111. Mulcahy LA, Pink RC, Carter DR. Routes and mechanisms of extracellular vesicle uptake. J Extracell Vesicles. (2014) 3:24641. doi: 10.3402/jev.v3.24641

112. Toribio V, Morales S, Lopez-Martin S, Cardenes B, Cabanas C, Yanez-Mo M. Development of a quantitative method to measure EV uptake. Sci Rep. (2019) 9:10522. doi: 10.1038/s41598-019-47023-9

113. Naslund TI, Paquin-Proulx D, Paredes PT, Vallhov H, Sandberg JK, Gabrielsson S. Exosomes from breast milk inhibit HIV-1 infection of dendritic cells and subsequent viral transfer to CD4+ $\mathrm{T}$ cells. AIDS. (2014) 28:171-80. doi: 10.1097/QAD.0000000000 000159

114. Horibe S, Tanahashi T, Kawauchi S, Murakami Y, Rikitake Y. Mechanism of recipient cell-dependent differences in exosome uptake. BMC Cancer. (2018) 18:47. doi: 10.1186/s12885-017-3958-1

115. Koponen A, Kerkela E, Rojalin T, Lazaro-Ibanez E, Suutari T, Saari $\mathrm{HO}$, et al. Label-free characterization and real-time monitoring of cell uptake of extracellular vesicles. Biosens Bioelectron. (2020) 168:112510. doi: 10.1016/j.bios.2020.112510

116. Zhuang X, Xiang X, Grizzle W, Sun D, Zhang S, Axtell RC, et al. Treatment of brain inflammatory diseases by delivering exosome encapsulated antiinflammatory drugs from the nasal region to the brain. Mol Ther. (2011) 19:1769-79. doi: 10.1038/mt.2011.164

117. Zhang D, Lee H, Zhu Z, Minhas JK, Jin Y. Enrichment of selective miRNAs in exosomes and delivery of exosomal miRNAs in vitro and in vivo. Am J Physiol Lung Cell Mol Physiol. (2017) 312:L110-L21. doi: 10.1152/ajplung.00423.2016

118. Zhang D, Lee H, Jin Y. Delivery of functional small RNAs via extracellular vesicles in vitro and in vivo. Methods Mol Biol. (2020) 2115:107-17. doi: 10.1007/978-1-0716-0290-4_6

119. Pomatto MAC, Bussolati B, D'Antico S, Ghiotto S, Tetta C, Brizzi $\mathrm{MF}$, et al. Improved loading of plasma-derived extracellular vesicles to encapsulate antitumor miRNAs. Mol Ther Methods Clin Dev. (2019) 13:13344. doi: 10.1016/j.omtm.2019.01.001

120. Lamichhane TN, Raiker RS, Jay SM. Exogenous DNA loading into extracellular vesicles via electroporation is size-dependent and enables limited gene delivery. Mol Pharm. (2015) 12:3650-7. doi: 10.1021/acs.molpharmaceut.5b00364

121. Jeyaram A, Lamichhane TN, Wang S, Zou L, Dahal E, Kronstadt $\mathrm{SM}$, et al. Enhanced loading of functional miRNA cargo via $\mathrm{pH}$ gradient modification of extracellular vesicles. Mol Ther. (2020) 28:975-85. doi: 10.1016/j.ymthe.2019.12.007

122. Harisa GI, Badran MM, Alanazi FK. Erythrocyte nanovesicles: biogenesis, biological roles and therapeutic approach: erythrocyte nanovesicles. Saudi Pharm J. (2017) 25:8-17. doi: 10.1016/j.jsps.2015. 06.010

123. Loyer X, Vion AC, Tedgui A, Boulanger CM. Microvesicles as cellcell messengers in cardiovascular diseases. Circ Res. (2014) 114:345-53. doi: 10.1161/CIRCRESAHA.113.300858

124. Jank H, Salzer U. Vesicles generated during storage of red blood cells enhance the generation of radical oxygen species in activated neutrophils. ScientificWorldJournal. (2011) 11:173-85. doi: 10.1100/tsw.2011.25 
125. Minetti M, Agati L, Malorni W. The microenvironment can shift erythrocytes from a friendly to a harmful behavior: pathogenetic implications for vascular diseases. Cardiovasc Res. (2007) 75:21-8. doi: 10.1016/j.cardiores.2007.03.007

126. Moreno PR, Purushothaman KR, Sirol M, Levy AP, Fuster V. Neovascularization in human atherosclerosis. Circulation. (2006) 113:2245-52. doi: 10.1161/CIRCULATIONAHA.105.578955

127. Buesing KL, Densmore JC, Kaul S, Pritchard KA, Jr., Jarzembowski JA, et al. Endothelial microparticles induce inflammation in acute lung injury. J Surg Res. (2011) 166:32-9. doi: 10.1016/j.jss.2010.05.036

128. Herring JM, McMichael MA, Smith SA. Microparticles in health and disease. J Vet Intern Med. (2013) 27:1020-33. doi: 10.1111/jvim.12128

129. Burnier L, Fontana P, Kwak BR, Angelillo-Scherrer A. Cell-derived microparticles in haemostasis and vascular medicine. Thromb Haemost. (2009) 101:439-51. doi: 10.1160/TH08-08-0521

130. Chung SM, Bae ON, Lim KM, Noh JY, Lee MY, Jung YS, et al. Lysophosphatidic acid induces thrombogenic activity through phosphatidylserine exposure and procoagulant microvesicle generation in human erythrocytes. Arterioscler Thromb Vasc Biol. (2007) 27:414-21. doi: 10.1161/01.ATV.0000252898.48084.6a

131. Lang E, Qadri SM, Lang F. Killing me softly - suicidal erythrocyte death. Int J Biochem Cell Biol. (2012) 44:1236-43. doi: 10.1016/j.biocel.2012.04.019

132. Kleinegris MC, Koek GH, Mast K, Mestrom EH, Wolfs JL, Bevers EM. Ribavirin-induced externalization of phosphatidylserine in erythrocytes is predominantly caused by inhibition of aminophospholipid translocase activity. Eur J Pharmacol. (2012) 693:1-6. doi: 10.1016/j.ejphar.2012.07.041

133. Tziakas DN, Chalikias GK, Stakos D, Boudoulas H. The role of red blood cells in the progression and instability of atherosclerotic plaque. Int J Cardiol. (2010) 142:2-7. doi: 10.1016/j.ijcard.2009.10.031

134. Tantawy AA, Adly AA, Ismail EA, Habeeb NM, Farouk A. Circulating platelet and erythrocyte microparticles in young children and adolescents with sickle cell disease: relation to cardiovascular complications. Platelets. (2013) 24:605-14. doi: 10.3109/09537104.2012.749397

135. Pham CT, Zhang X, Lam A, Le MT. Red blood cell extracellular vesicles as robust carriers of RNA-based therapeutics. Cell Stress. (2018) 2:239-41. doi: $10.15698 /$ cst2018.09.155

136. Byrnes JR, Wolberg AS. Red blood cells in thrombosis. Blood. (2017) 130:1795-9. doi: 10.1182/blood-2017-03-745349

137. Svensson KJ, Christianson HC, Wittrup A, Bourseau-Guilmain E, Lindqvist E, Svensson LM, et al. Exosome uptake depends on ERK1/2heat shock protein 27 signaling and lipid Raft-mediated endocytosis negatively regulated by caveolin-1. J Biol Chem. (2013) 288:17713-24. doi: 10.1074/jbc.M112.445403

138. Armstrong JPK, Stevens MM. Strategic design of extracellular vesicle drug delivery systems. Adv Drug Deliv Rev. (2018) 130:12-6. doi: 10.1016/j.addr.2018.06.017

139. Kao CY, Papoutsakis ET. Extracellular vesicles: exosomes, microparticles, their parts, and their targets to enable their biomanufacturing and clinical applications. Curr Opin Biotechnol. (2019) 60:89-98. doi: 10.1016/j.copbio.2019.01.005

140. Prada I, Meldolesi J. Binding and fusion of extracellular vesicles to the plasma membrane of their cell targets. Int J Mol Sci. (2016) 17:1296. doi: 10.3390/ijms17081296

141. Jiang J, Kao CY, Papoutsakis ET. How do megakaryocytic microparticles target and deliver cargo to alter the fate of hematopoietic stem cells? J Control Release. (2017) 247:1-18. doi: 10.1016/j.jconrel.2016.12.021

142. Borgheti-Cardoso LN, Kooijmans SAA, Chamorro LG, Biosca A, Lantero E, Ramirez M, et al. Extracellular vesicles derived from plasmodium-infected and non-infected red blood cells as targeted drug delivery vehicles. Int J Pharm. (2020) 587:119627. doi: 10.1016/j.ijpharm.2020.119627

143. Wiley JS, McCulloch KE, Bowden DS. Increased calcium permeability of cold-stored erythrocytes. Blood. (1982) 60:92-8. doi: 10.1182/blood.V60.1.92.92

144. Rinalducci S, Ferru E, Blasi B, Turrini F, Zolla L. Oxidative stress and caspase-mediated fragmentation of cytoplasmic domain of erythrocyte band 3 during blood storage. Blood Transfus. (2012) 10 (Suppl. 2):s55-62. doi: $10.2450 / 2012.009$ S
145. D’Amici GM, Rinalducci S, Zolla L. Proteomic analysis of RBC membrane protein degradation during blood storage. J Proteome Res. (2007) 6:3242-55. doi: $10.1021 /$ pr070179d

146. Wither M, Dzieciatkowska M, Nemkov T, Strop P, D’Alessandro A, Hansen KC. Hemoglobin oxidation at functional amino acid residues during routine storage of red blood cells. Transfusion. (2016) 56:421-6. doi: $10.1111 /$ trf.13363

147. Gevi F, D’Alessandro A, Rinalducci S, Zolla L. Alterations of red blood cell metabolome during cold liquid storage of erythrocyte concentrates in CPDSAGM. J Proteomics. (2012) 76:168-80. doi: 10.1016/j.jprot.2012.03.012

148. Almizraq RJ, Holovati JL, Acker JP. Characteristics of extracellular vesicles in red blood concentrates change with storage time and blood manufacturing method. Transfus Med Hemother. (2018) 45:185-93. doi: 10.1159/000486137

149. Bicalho B, Pereira AS, Acker JP. Buffy coat (top/bottom)- and wholeblood filtration (top/top)-produced red cell concentrates differ in size of extracellular vesicles. Vox Sang. (2015) 109:214-20. doi: 10.1111/vox.12272

150. Shrestha RP, Horowitz J, Hollot CV, Germain MJ, Widness JA, Mock DM, et al. Models for the red blood cell lifespan. J Pharmacokinet Pharmacodyn. (2016) 43:259-74. doi: 10.1007/s10928-016-9470-4

151. Soekmadji C, Li B, Huang Y, Wang H, An T, Liu C, et al. The future of extracellular vesicles as theranostics - an ISEV meeting report. J Extracell Vesicles. (2020) 9:1809766. doi: 10.1080/20013078.2020.1809766

152. Clayton A, Boilard E, Buzas EI, Cheng L, Falcon-Perez JM, Gardiner $\mathrm{C}$, et al. Considerations towards a roadmap for collection, handling and storage of blood extracellular vesicles. J Extracell Vesicles. (2019) 8:1647027. doi: 10.1080/20013078.2019.1647027

153. Meng W, He C, Hao Y, Wang L, Li L, Zhu G. Prospects and challenges of extracellular vesicle-based drug delivery system: considering cell source. Drug Deliv. (2020) 27:585-98. doi: 10.1080/10717544.2020.1748758

154. Ge Q, Zhou Y, Lu J, Bai Y, Xie X, Lu Z. miRNA in plasma exosome is stable under different storage conditions. Molecules. (2014) 19:1568-75. doi: 10.3390/molecules19021568

155. Catalano M, O’Driscoll L. Inhibiting extracellular vesicles formation and release: a review of EV inhibitors. J Extracell Vesicles. (2020) 9:1703244. doi: 10.1080/20013078.2019.1703244

156. O’Brien K, Breyne K, Ughetto S, Laurent LC, Breakefield XO. RNA delivery by extracellular vesicles in mammalian cells and its applications. Nat Rev Mol Cell Biol. (2020) 21:585-606. doi: 10.1038/s41580-020-0251-y

157. Rumsby MG, Trotter J, Allan D, Michell RH. Recovery of membrane microvesicles from human erythrocytes stored for transfusion: a mechanism for the erythrocyte discocyte-to-spherocyte shape transformation. Biochem Soc Trans. (1977) 5:126-8. doi: 10.1042/bst0050126

158. Sheng L, Stewart T, Yang D, Thorland E, Soltys D, Aro P, et al. Erythrocytic alpha-synuclein contained in microvesicles regulates astrocytic glutamate homeostasis: a new perspective on Parkinson's disease pathogenesis. Acta Neuropathol Commun. (2020) 8:102. doi: 10.1186/s40478-020-00983-w

159. Kidd L, Geddings J, Hisada Y, Sueda M, Concannon T, Nichols T, et al. Procoagulant microparticles in dogs with immune-mediated hemolytic anemia. J Vet Intern Med. (2015) 29:908-16. doi: 10.1111/jvim.12583

160. Arvidsson I, Stahl AL, Hedstrom MM, Kristoffersson AC, Rylander C, Westman JS, et al. Shiga toxin-induced complement-mediated hemolysis and release of complement-coated red blood cell-derived microvesicles in hemolytic uremic syndrome. J Immunol. (2015) 194:2309-18. doi: 10.4049/jimmunol.1402470

161. Mantel PY, Hoang AN, Goldowitz I, Potashnikova D, Hamza B, Vorobjev I, et al. Malaria-infected erythrocyte-derived microvesicles mediate cellular communication within the parasite population and with the host immune system. Cell Host Microbe. (2013) 13:521-34. doi: 10.1016/j.chom.2013.04.009

162. Bevers EM, Wiedmer T, Comfurius P, Shattil SJ, Weiss HJ, Zwaal RF, et al. Defective $\mathrm{Ca}(2+)$-induced microvesiculation and deficient expression of procoagulant activity in erythrocytes from a patient with a bleeding disorder: a study of the red blood cells of Scott syndrome. Blood. (1992) 79:380-8. doi: 10.1182/blood.V79.2.380.380

163. Chen Y, Li G, Liu ML. Microvesicles as emerging biomarkers and therapeutic targets in cardiometabolic diseases. Genomics Proteomics Bioinformatics. (2018) 16:50-62. doi: 10.1016/j.gpb.2017.03.006 
164. Boulanger CM, Loyer X, Rautou PE, Amabile N. Extracellular vesicles in coronary artery disease. Nat Rev Cardiol. (2017) 14:259-72. doi: $10.1038 /$ nrcardio.2017.7

Conflict of Interest: The authors declare that the research was conducted in the absence of any commercial or financial relationships that could be construed as a potential conflict of interest.

Publisher's Note: All claims expressed in this article are solely those of the authors and do not necessarily represent those of their affiliated organizations, or those of the publisher, the editors and the reviewers. Any product that may be evaluated in this article, or claim that may be made by its manufacturer, is not guaranteed or endorsed by the publisher.

Copyright (c) 2021 Chiangjong, Netsirisawan, Hongeng and Chutipongtanate. This is an open-access article distributed under the terms of the Creative Commons Attribution License (CC BY). The use, distribution or reproduction in other forums is permitted, provided the original author(s) and the copyright owner(s) are credited and that the original publication in this journal is cited, in accordance with accepted academic practice. No use, distribution or reproduction is permitted which does not comply with these terms. 